\title{
Diagnostic value and cost-benefit analysis of 24 hours ambulatory blood pressure monitoring in primary care in Portugal
}

\author{
Paulo Pessanha', Manuel Viana', Paula Ferreira', Susana Bertoquini ${ }^{1}$ and Jorge Polónia ${ }^{3^{*}}$
}

\begin{abstract}
Background: Hypertensive patients ( $\mathrm{HTS}$ ) are usually attended in primary care (PC). We aimed to assess the diagnostic accuracy and cost-benefit ratio of 24-hour ambulatory blood pressure monitoring (ABPM) in all newly diagnosed hypertensive patients (HTs) attended in PC.

Methods: In a cross-sectional study ABPM was recorded in all 336 never treated HTs (Office BP $\geq 140$ and/or $\geq$ $90 \mathrm{~mm} \mathrm{Hg}$ ) that were admitted during 16 months. Since benefits from drug treatment in white-coat hypertension (WCH) remain unproven, a cost benefit estimation of a general use of ABPM (vs absence of ABPM) in HTs was calculated comparing the cost of usual medical assistance of HTs only diagnosed in office with that based both on refraining from drug treatment all subjects identified as WCH and on the reduction by half of the frequency of biochemical exams and doctor visits.

Results: Women were $56 \%$, age $51 \pm 14$ years and BMI $27 \pm 4 \mathrm{Kg} / \mathrm{m} 2$. Out of these, 206 were considered as true HTs, daytime $A B P M \geq 135$ and/or $\geq 85 \mathrm{~mm} \mathrm{Hg}$ and 130 (38,7\%) were identified as having white coat hypertension (WCH), daytime ABPM $<135 / 85 \mathrm{~mm} \mathrm{Hg}$. Versus HTs, WCH group showed higher percentage of women (68\% vs $51 \%$ ) and lower values of an index composed by the association of cardiovascular risk factors. We estimated that with ABPM total medical expenses can be reduced by 23\% (157.500 euros) with a strategy based on ABPM for 1000 patients followed for 2 years.

Conclusions: In PC, the widespread use of ABPM in newly diagnosed HTs increases diagnostic accuracy of hypertension, improves cardiovascular risk stratification, reduces health expenses showing a highly favourable benefit-cost ratio vs a strategy without ABPM.
\end{abstract}

Keywords: Hypertension, Ambulatory blood pressure monitoring (ABPM), General practice/Family medicine, White coat hypertension (WCH), Cardiovascular risk factors, ABPM cost-benefit

\section{Background}

Hypertension (HT) is a recognized public health problem and is considered the leading cause of death throughout the world $[1,2]$. It is particularly responsible for the occurrence of fatal and non fatal cardiovascular events and deaths, including stroke and coronary heart disease [1,2]. HT is a chronic disease with an estimated prevalence of $40-45 \%$ in adults [3-5] that in most cases requires periodic monitoring, non-pharmacological and pharmacological therapy for a lifetime [1-5]. The

\footnotetext{
* Correspondence: jjpolonia@gmail.com

${ }^{3}$ Faculdade de Medicina da Universidade do Porto, Porto, Portugal Full list of author information is available at the end of the article
}

diagnosis of hypertension is associated with personal, social and economic disturbances with a noteworthy impact to the patient, to the health system and to the society [1-5]. General Practionerrs (GP) have an important role in the global approach to the hypertensive patient, concerning the diagnosis, treatment and regular monitoring. Actually, the great majority of the hypertensive situations are diagnosed and followed by the GP in primary care. It is now generally recognized that blood pressure (BP) measurement in office has several limitations. In recent years it has been shown that the evaluation of BP with ABPM for 24 hours has several advantages as compared to the

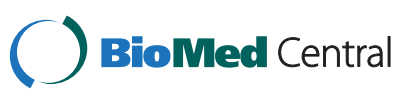


BP measurement in office, namely a greater validity and reproducibility and higher predictive value of fatal and non-fatal cardiovascular events [4,6-15]. Furthermore, ABPM allows multiple BP measurements during $24 \mathrm{~h}$ that may be more representative of the daily $\mathrm{BP}$ burden, permits the evaluation of $\mathrm{BP}$ during the daily activities away of the BP alert reaction observed in office and allows the assessment of BP during sleep $[9,11,14,16]$. Also, ABPM may identify some BP profiles such as the nocturnal fall of BP and the morning rise of $\mathrm{BP}$, which abnormal patterns have been shown to be independent predictors of target-organ damage and of risk of cardiovascular events [17-20]. Besides, ABPM allows the identification of individuals with the so called White Coat Hypertension (WCH) who shows hypertensive values in office but normal BP outside the doctor's office $[5,10,21,22]$. In the absence of target organ damage, WCH show an estimated prevalence between 18 and $40 \%[3,5]$ is associated with a low cardiovascular risk [1,14,23-25] for which evidence of benefit from drug treatment is lacking. Therefore recent "guidelines" [1] have suggested that, in the absence of target organ damage or previous events there is no clear justification to initiate pharmacologic treatment in subjects with $\mathrm{WCH}$ although periodic monitoring (including a ABPM/year) and surveillance is required. Thus ABPM may be considered an important technique for evaluation of new hypertensive patients even in the primary care setting. There are virtually no studies totally performed in primary care that have so far evaluated the diagnostic accuracy of the ABPM and its discriminative value of cardiovascular risk. Thus based on the identification of $\mathrm{WCH}$ with ABPM, the aim of this study was to assess the diagnostic accuracy and to determine the cost-benefit ratio of 24-hour ambulatory blood pressure monitoring (ABPM) in a population of newly diagnosed and previously untreated hypertensive patients (HTs) attended in primary care.

\section{Methods}

We conducted a cross-sectional and analytical observational study consisting on the analysis of the ABPM results and other clinical variables, taken from all 360 newly hypertensives patients diagnosed from July 2006 to November 2007 by their GP. All patients were fully observed in the Health Center of São João in Oporto and ABPM evaluation was performed in all patients before any treatment was prescribed. All study was carried out in compliance with the Helsinki Declaration, and its protocol was approved by the Ethical Committee of Centro Saude S. Joao, Porto, Faculdade Medicina do Porto 4/2006 and all patients participated the study under their written informed consent. The following variables were recorded: office BP, data from ABPM, gender, age, BMI, smoking habits, dyslipidemia, diabetes mellitus and family history of cardiovascular disease. Office BP values (phases I and V of Korotkoff) were redorded in the left arm with Omron M6 sphygmomanometer (average of 3 recordings with 5 min apart), using an appropriate bladder, after resting for 10 minutes in a sitting position and repeated 8-15 days thereafter. For ABPM data were used a SpaceLabs 90207 device (SpaceLabs Inc, Redmond, Washington, USA), connected to the non-dominant arm. Blood pressure was recorded during a normal working day with intervals of $20 / 20$ minutes during the daytime (07:00 to 23:00) and of 30/30 minutes during the nighttime resting period (23:30 to $06: 30)$. The nocturnal fall of BP was determined by the (average daytime $\mathrm{BP}$ - average nighttime $\mathrm{BP}$ )/daytime average $\mathrm{BP} \times$ 100. Patients were classified as dippers for nocturnal systolic BP decline between 10-19,9\%, non - dippers for nocturnal BP decline between 0-9,9\%, inverted-dippers for nocturnal BP decline between $<0 \%$ and the extreme dipper for nocturnal BP fall $\geq 20 \%$. Normotension was defined if casual BP was $<140 \mathrm{~mm} \mathrm{Hg}$ (SBP) and $<90 \mathrm{~mm}$ $\mathrm{Hg}$ (DBP) and values of the average daytime ambulatory $\mathrm{BP}<135$ and $<85 \mathrm{~mm} \mathrm{Hg}$. Hypertension was defined for casual BP values $\geq 140$ and/or $90 \mathrm{~mm} \mathrm{Hg}$ and average daytime ambulatory $\mathrm{BP} \geq 135$ and/or $85 \mathrm{~mm} \mathrm{Hg}$. WCH was defined for casual BP values $\geq 140$ and/or $90 \mathrm{~mm} \mathrm{Hg}$ and values of average daytime ambulatory BP $<135$ and $<85 \mathrm{~mm} \mathrm{Hg}$. Concerning the presence of cardiovascular risk factors we established an index of overall risk per patient resulting from the arithmetic sum of each one (presence $=1$, absence $=0$ ) of the following risk factors: ageing $>65$ years in women and $>55$ years in women, obesity (BMI $\geq 30 \mathrm{~kg} / \mathrm{m} 2)$, dyslipidemia i.e. total cholesterol $>190 \mathrm{mg} / \mathrm{dl}$ ) and/or HDL-C $<46 \mathrm{mg} /$ $\mathrm{dl}$ women and $<40 \mathrm{mg} / \mathrm{dl}$ men, and/or triglycerides $>$ $150 \mathrm{mg} / \mathrm{dl}$, smoking and family (first and second degree relatives) history of cardiovascular events before 65 years.

We used a model to calculate cost-effectiveness of ABPM in primary care taking into account the cost of medical assistance (drug treatment, medical visits and laboratorial evaluation) of hypertensive patients diagnosed in office vs the cost of medical assistance with a strategy based on use of ABPM hypertensive patients, allowing to select true hypertensives and subjects with WCH.

The model was estimated for a total of 1000 patients diagnosed as hypertensives according to BP measured in office and followed-up for 2 years with and without information of ABPM data. The following parameters were considered: a) Prevalence of $\mathrm{WCH}$ in the initial evaluation by ABPM; b) cost of ABPM (65 euros/registration), c) cost of treatment antihypertensive (0.65 euros/day, when indicated, d) cost of routine analytical evaluation in 
hypertensive patients (14.42 euros for each assessment) and of the minimum number of medical visits (cost 41 euros/visits, e) the cost of medical visits considered minimally required i.e. two medical visits and two analytical evaluations per year for all hypertensives diagnosed in office without ABPM evaluation and for all true hypertensive patients confirmed by ABPM versus a single visit and a single analytical evaluation per year for individuals with WCH), e) gain (savings) estimated in euros for the period of 2 years using ABPM (avoiding pharmacological treatment in individuals with $\mathrm{WCH}$ and half reducing the number of medical visits and screening summary) minus the cost of ABPM versus the cost of medical assistance in all patients diagnosed as hypertensive in the absence of use of ABPM. The estimation of cost of drug therapy was based on "Medicinal products for human use for use in outpatient clinic, INFARMED, Portugal 2006" and the cost of medical ambulatory visits and of diagnostic procedures was based on Portuguese National Health System 2006 price list of diagnostic techniques [26].

\section{Statistical analysis}

The SPSS (Statistical Package for Social Science) version 12.0 was used to perform statistical analysis. Parametric data are as average of $\pm \mathrm{SD}$. We used the chi-square to compare groups for categorical variables. The differences between the group of sustained hypertensives and the group of subjects with white-coat hypertension events were obtained by statistical parameter using the $t$ test Student for independent groups, analyzing the following variables: age, sex, biochemical variables, casual BP, 24hour, daytime and nightime records of ABPM. All tests were considered statistically significant for significance level (p) $<0.05$.

\section{Results}

Office BP and ABPM evaluations were performed in 360 patients with newly hypertension diagnosed in office, without antihypertensive medications who were attended in General Practice/Family Medicine between July 2006 and November 2007 (16 months). Out of these, 24 individuals were excluded since casual $\mathrm{BP}$ in the second recording day evolve towards normotensive values. Therefore for this study we included 336 individuals, $56 \%$ women, ageing $51 \pm 14(15-82)$ years, BMI $26.5 \pm 4$ (17-41) $\mathrm{kg} / \mathrm{m} 2 ; 3.3 \%$ were diabetics, $20.8 \%$ had BMI > $29.9 \mathrm{~kg} / \mathrm{m} 2,20.2 \%$ were smokers, $44.6 \%$ had dyslipidemia, $3 \%$ had previous strokes and $1 \%$ previous coronary even and $15.5 \%$ had a family history of hypertension. After ABPM we identified 206 as true hypertensive patients (HTs, 61.3\%) and 130 as having white coat hypertension (WCH, 38.7\%). Table 1 summarizes and compares the clinical characteristics of these two subgroups. Compared to $\mathrm{WCH}$, the HTs showed significantly higher levels of casual BP, mean $24 \mathrm{~h}$, daytime and nighttime ambulatory pressures, blood pressure on awakening and 24-hour heart rate. The group of HTs also showed significantly higher blood levels of triglycerides, and of the composite index made by the association of various cardiovascular risk factors. Also, the percentage of males and smokers was significantly greater in HTs vs WCH groups and there were not statistically significant differences concerning the percentage of obese, of diabetics and of patients with dyslipidemia. As shown, there were no statistically significant differences between HTs and WCH regarding age, BMI, blood levels of fasting glucose and total cholesterol and HDL-C sub fraction. Also there were no differences between groups for different patterns of nocturnal decline in BP. Table 2 shows the calculation of cost of medical resources of either strategies with and without the contribution of ABPM, estimated for 1000 hypertensive patients classified with office BP followed for two years. Based on data from the present study we considered that after ABPM, WCH would be diagnosed in $38 \%$ of the hypertensive patients identified only with office BP. As shown, on the strategy without ABPM and according to guidelines [27] all hypertensive patients diagnosed in office as well as all true hypertensive patients diagnosed with ABPM should be treated with antihypertensive drugs and submitted per year at least to two doctor visits and to two routine biochemical evaluations. In contrast follow-up of subjects with WCH (i.e. $38 \%$ of all hypertensive patients diagnosed in office) could be restrained per year to a single doctor visit and to a single routine biochemical evaluation whereas they also should perform an ABPM recording every year. Despite of ABPM strategy involving the additional cost of this examination we can obtain an overall saving of about $23 \%$ of resources i.e. corresponding to around 157,500 euros for 1000 patients followed for two years in general practice.

\section{Discussion}

The aim of this study was to evaluate in Primary Care, the diagnostic value and cost-effectiveness of ABPM in Primary Care in newly diagnosed hypertensive patients. Because benefits from drug treatment in white-coat hypertension (WCH) remain unproven, we estimated that the avoidance of drug treatment and the reduction of other medical care expenses in the $38 \%$ of the hypertensive patients diagnosed as having WCT would represent an overall significant saving of medical resources and cost of therapy if 24-hour ABPM was generalized to all hypertensive patients diagnosed only on the basis of casual BP measurements.

The importance of ABPM in the diagnosis, monitoring and prognostic stratification of hypertensive patients is clearly defined in literature [1,7-9,11-14,22,28-32]. $\mathrm{ABPM}$ is considered a simple and noninvasive technique 
Table 1 Anthropometric characteristics and values of casual blood pressure, ambulatory BP and of biochemical data in individuals classified as WCH and HTs

\begin{tabular}{|c|c|c|c|}
\hline & $\begin{array}{c}\text { WCH } \\
(n=130)\end{array}$ & $\begin{array}{c}\text { HTs } \\
(n=206)\end{array}$ & $p$ \\
\hline Age (years) & $50 \pm 14$ & $52 \pm 14$ & 0.27 \\
\hline Women (\%) & 68 & 51 & $<0.05$ \\
\hline BMI $\left(\mathrm{kg} / \mathrm{m}^{2}\right)$ & $26 \pm 4$ & $27 \pm 4$ & 0.35 \\
\hline BMI > $29.9 \mathrm{Kg} / \mathrm{m} 2(\%)$ & 18 & 23 & 0.32 \\
\hline Smokers (\%) & 14 & 24 & $<0,01$ \\
\hline Dyslipidemia (\%) & 38 & 47 & $<0.05$ \\
\hline Diabetes (\%) & 2.3 & 3.9 & 0.19 \\
\hline Family history of CV disease (\%) & 13 & 20 & 0.23 \\
\hline Office SBP (mm Hg) & $154 \pm 12$ & $161 \pm 15$ & $<0,001$ \\
\hline Office DBP (mm Hg) & $92 \pm 10$ & $94 \pm 9$ & $<0,05$ \\
\hline 24 h SBP (mm Hg) & $120 \pm 6$ & $135 \pm 10$ & $<0,001$ \\
\hline $24 \mathrm{~h}$ DBP $(\mathrm{mm} \mathrm{Hg})$ & $73 \pm 5$ & $85 \pm 7$ & $<0,001$ \\
\hline $24 \mathrm{~h} \mathrm{PP}(\mathrm{mm} \mathrm{Hg})$ & $47 \pm 6$ & $51 \pm 9$ & $<0,001$ \\
\hline $24 \mathrm{~h}$ Heart rate (beats/min) & $73 \pm 9$ & $77 \pm 9$ & $<0,001$ \\
\hline Daytime SBP (mm Hg) & $124 \pm 6$ & $140 \pm 10$ & $<0,001$ \\
\hline Daytime DBP day $(\mathrm{mm} \mathrm{Hg})$ & $77 \pm 5$ & $89 \pm 8$ & 0.052 \\
\hline Nighttime SBP (mm Hg) & $113 \pm 8$ & $126 \pm 12$ & $<0,001$ \\
\hline Nighttime DBP day $(\mathrm{mm} \mathrm{Hg})$ & $66 \pm 6$ & $76 \pm 8$ & $<0,001$ \\
\hline Nocturnal SBP fall (\%) & $8,7 \pm 5,6$ & $10,1 \pm 5,6$ & $<0,05$ \\
\hline Inverted-dipper (\%) & 2 & 4 & 0.44 \\
\hline Non-dipper (\%) & 43 & 46 & 0.62 \\
\hline Dipper (\%) & 46 & 47 & 0.71 \\
\hline Extreme-dipper (\%) & 9 & 3 & 0.11 \\
\hline SBP on awakening $(\mathrm{mm} \mathrm{Hg})$ & $116 \pm 15$ & $134 \pm 17$ & $<0,001$ \\
\hline Total Cholesterol (mg/dl) & $216 \pm 37$ & $220 \pm 39$ & 0.12 \\
\hline $\mathrm{HDL}-\mathrm{C}(\mathrm{mg} / \mathrm{dl})$ & $58 \pm 15$ & $54 \pm 17$ & 0.14 \\
\hline Tryglicerides (mg/dl) & $128 \pm 83$ & $160 \pm 124$ & $<0,05$ \\
\hline Glicemia (mg/dl) & $95 \pm 19$ & $101 \pm 26$ & 0.09 \\
\hline numRF (n) & $1,15 \pm 0,90$ & $1,44 \pm 0,98$ & $<0,05$ \\
\hline
\end{tabular}

Values expressed as average \pm standard deviation.

WCH White Coat Hypertensive, HTS Sustained Hypertensive, BMI Body Mass Index, SBP Systolic blood pressure, DBP Diastolic blood pressure, $H R$ heart rate; $P P$ Pulse Pressure, numRF Number of risk factors, $p$ level of significance. with a higher diagnostic accuracy comparing to office BP providing exclusive data on the blood pressure profile in real life outside the medical office [1,7-9,11-14,22,28-32]. ABPM is a valuable tool for the diagnosis of masked hypertension a condition cursing with normotensive values in office and abnormally high pressure values outside the office setting that has been associated with an increased incidence target organ damage [33]. ABPM also allows to identify those individuals with white coat hypertension/isolated office hypertension (WCH) $[1,4,6,12,16,21,24,34,35]$ who exhibit a high blood pressure values in the doctor's office in contrast with normal blood pressure values outside that setting. WCH cannot be diagnosed reliably on clinical examination alone. Both ABPM and home blood pressure monitoring (HBPM) overcomes many of the limitations of traditional office blood pressure (BP) measurement and are the mostly used tools for the diagnosis of white-coat hypertension [1]. Home readings are more reproducible than office readings and show better correlations with measures of target organ damage [12]. Since it is less influenced by the white-coat effect HBPM contributes for the diagnosis of $\mathrm{WCH}$. However, using ABPM as a reference, it has been shown a lower accuracy, specificity and sensitivity of HBPM to detect white coat hypertension [36] and that HBPM may not be completely devoid of white-coat effects [37]. Although there are some potential cost-effectiveness advantages for the use of HBPM in the diagnosis and management of hypertension by reducing the need for office visits, the net cost of home blood pressure monitorings and the absence of reimbursement by National Health Systems, as it occurs in Portugal, limits it generalization to a broad population and threatens its potential costeffectiveness [38]. WCH has been associated with a low cardiovascular risk profile at least while comparing to sustained hypertensives [1,4,8,11,14,23-25,39]. Careful surveillance and implementation of healthy lifestyles but not pharmacological therapy has been recommended in $\mathrm{WCH}[1,4,24,25]$ and no study has so far clearly proven that drug treatment provides any benefit. Thus, the identification of $\mathrm{WCH}$ may have important consequences in reducing medical expenses

Table 2 Reducing costs on medical resources with the use of ABPM in 1000 hypertensive patients followed at the doctor's office for 2 years, allowing the identification of WCH (prevalence of $38 \%$ )

\begin{tabular}{|c|c|c|c|c|c|c|c|}
\hline $\begin{array}{l}1000 \text { patients } \\
\text { followed for } \\
2 \text { years }\end{array}$ & $\begin{array}{c}\text { Prevalence } \\
\text { of HT } \\
\text { to treat }\end{array}$ & $\begin{array}{c}\text { Cost of treatment } \\
\text { in Euros } \\
(0,65 \text { Euros/day })\end{array}$ & $\begin{array}{c}\text { Doctor } \\
\text { visits cost } \\
\text { (41 Euros/visit) }\end{array}$ & $\begin{array}{c}\text { Biochemical } \\
\text { analysis cost } \\
(14,42 \text { euros/analysis })\end{array}$ & $\begin{array}{c}\text { ABPM cost } \\
65 \text { Euros/ABPM }\end{array}$ & $\begin{array}{c}\text { Total cost } \\
\text { (euros/2 years) }\end{array}$ & $\begin{array}{c}\text { ABPM } \\
\text { saving strategy } \\
\text { (euros/2 years) }\end{array}$ \\
\hline Without ABPM & $100 \%$ & 474500 & 164000 & 57680 & 0 & 696180 & 0 \\
\hline With ABPM & $62 \%$ & 294190 & 132840 & 46721 & 65000 & 538751 & 157429 \\
\hline \multicolumn{2}{|c|}{ \% ABPM saving strategy } & & & & & & $22,6 \%$ \\
\hline
\end{tabular}


related with drug treatment of hypertension, reducing the need of medical visits and exams [40]. Almost all studies using 24 hours ABPM have been made so far in hospitals. i.e. outside the Primary Health Care Centers. Since hypertension is highly prevalent in general adult population (about $40 \%$ of adult population) most patients are diagnosed, evaluated and followed in general practice. In our study, for the estimation of the diagnostic value and cost-effectiveness of ABPM in Primary Care we evaluated clinically and with ABPM 336 adult patients with newly diagnosed office hypertension, that in $38.7 \%$ were fulfilling the diagnosis of white coat hypertension. This percentage of $\mathrm{WCH}$ as well as a higher number of women in this group is consistent with that found in the literature $[3,5,12,13]$ particularly concerning the hypertensive population with stage 1 and 2 hypertension at the office, i.e. the population that is more frequently observed in Primary Health Care. For a similar age and BMI distribution, the group of individuals with sustained hypertension shoed higher casual blood pressure and 24-hour ABPM values comparing to $\mathrm{WCH}$. True hypertensives also showed a worse profile of global cardiovascular risk as expressed in the coexistence of a cumulative aggregate of cardiovascular risk factors, beyond the office BP levels. Also, office BP and ABPM values were higher in HTs individuals than in those with $\mathrm{WCH}$. Thus, the present study confirms that patients with $\mathrm{WCH}$ show several indicators of a lower cardiovascular risk than patients with sustained hypertension. There is now consensus that individuals with WCH require medical supervision but benefit from pharmacological treatment is unproven $[1,24,25,29]$. Thus the diagnosis of this condition could have important implications in reducing health expenses on medication, medical visits and diagnostic exams that could result in the reduction of iatrogenic risks and of direct and indirect (personal, family and social, etc.) costs.

In the present study we estimated the cost benefit of two strategies of monitoring of newly diagnosed hypertensive patients based and not based on the general use of 24-h BPM in Primary Health Care. With ABPM we were able to identify $38 \%$ of the hypertensive patients diagnosed in office as having WCT. Although ABPM strategy implied an increased cost related with generalized 24-h BP monitoring procedure, there was a significant saving of medical resources and cost of therapy since these subjects were not only restrained from drug treatment but also doctor visits and routine biochemical evaluation were reduced by half as compared with sustained hypertensives.

Considering the high prevalence of the $\mathrm{WCH}$ found in the newly diagnosed hypertensive population, our study clearly suggests that the implementation of a strategy of widespread use of ABPM in Primary Care provides a highly favourable cost-benefit ratio. Our estimation for 1000 patients followed for 2 years showed that it is possible to reduce about $23 \%$ of total medical expenses with a strategy based on ABPM vs no use of ABPM. In other words ABPM based strategy reduced overall expenses by 157.500 euros per 1000 patients evaluated for two years. These data agree to those of other studies in which ABPM showed a favourable benefit-cost ratio for optimizing therapy $[24,40]$ and for reducing the number of antihypertensive drugs needed in patients with sustained hypertension under chronic treatment [41]. Meanwhile, our estimation did not take into account any additional gain resulting from the avoidance of possible drug side effects and iatrogenic related costs associated with the massive and widespread use of medication in subjects for whom the benefits of therapy have not been proved. Our study has limitations. Beyond the factor related with the relatively small dimension of our sample it is generally assumed that 24-h ABPM is not easily available to all Private care Doctors thereby limiting the generalization of this method. Secondly it is not clear whether subjects with WCH who has concomitant other risk factors beyond office hypertension or underlying diseases do not require the immediate start of anti-hypertensive treatment. Also in our study there was another expected inconvenience related to a possible misdiagnosis of hypertension at entry while based only in casual BP evaluation that could lead to the inclusion in the $\mathrm{WCH}$ group some real normotensive subjects.

\section{Conclusions}

In conclusion our study shows that in Primary Health Care, the strategy based on the widespread use of 24hour ABPM in newly diagnosed hypertensive patients has a highly favourable benefit-cost ratio in comparison with a strategy without ABPM. The former strategy allows to reduce by $23 \%$ the overall costs associated with the implementation of therapy and of medical diagnosis and monitoring procedures. Our data may support the widespread implementation of the ABPM technique in general medicine/family practice within the approach of newly hypertensive patients, by contributing to increase diagnostic accuracy of hypertension, to improve risk stratification and to reduce the costs and the iatrogenic drug risks.

\section{Competing interests \\ All authors declare that they have no financial or non-financial competing interests concerning the present study.}

\section{Authors' contributions}

PP was the doctor responsible for local supervision of the collection of clinical data and also attended $40 \%$ of the included subjects. MV and PF were the clinicians who attended more than $60 \%$ of the patients thereby performing the collection of clinical data. SB was responsible for collection of ABPM data and to include it in a data base. JP conceived the study and its design, wrote the manuscript, elaborate the answers to the reviewers and 
performed the statistical analysis. All authors equally participate in the general design of the study and in the discussion of the results. All authors read and approved the final manuscript.

\section{Acknowledgements}

Trabalho premiado com Menção Honrosa, Premio Bial 2009.

\section{Author details}

${ }^{1}$ Health Center of São João, Porto, Portugal. ${ }^{2}$ Faculdade Psicologia e Ciências da Educação, Bolseira FCT, Porto, Portugal. ${ }^{3}$ Faculdade de Medicina da Universidade do Porto, Porto, Portugal.

Received: 5 December 2012 Accepted: 23 July 2013

Published: 12 August 2013

\section{References}

1. Mancia G, De Backer G, Dominiczak A, et al: 2007 European society of hypertension-European society of cardiology guidelines for the management of arterial hypertension. J Hypertens 2007, 25:1105-1187.

2. Chobanian AV, Bakris GL, Black HR, et al: The seventh report of the joint national committee on prevention, detection, evaluation, and treatment of high blood pressure: the JNC 7 report. Jama 2003, 289(19):2560-2572.

3. MacDonald MB, Laing GP, Wilson MP, Wilson TW: Prevalence and predictors of white-coat response in patients with treated hypertension [see comments]. Cmaj 1999, 161(3):265-269.

4. Kario K, Pickering TG: Survey of white coat hypertension: definition differs from others [letter; comment]. Bmj 1999, 318(7182):535.

5. Pickering TG, James GD, Boddie C, Harshfield GA, Blank S, Laragh JH: How common is white coat hypertension? Jama 1988, 259(2):225-228.

6. Aylett MJ: Ambulatory or self blood pressure measurement? Improving the diagnosis of hypertension. Fam Pract 1994, 11(2):197-200.

7. Feola M, Boffano GM, Procopio M, Reynaud S, Allemano P, Rizzi G: Ambulatory 24-hour blood pressure monitoring: correlation between blood pressure variability and left ventricular hypertrophy in untreated hypertensive patients. G Ital Cardiol 1998, 28(1):38-44.

8. Imai Y: Prognostic significance of ambulatory blood pressure. Blood Press Monit 1999, 4(5):249-256.

9. Kario K, Matsuo T, Kobayashi H, Imiya M, Matsuo M, Shimada K: Nocturnal fall of blood pressure and silent cerebrovascular damage in elderly hypertensive patients: advanced silent cerebrovascular damage in extreme dippers. Hypertension 1996, 27(1):130-135

10. Mancia $G$, et al: Ambulatory blood pressure is superior to clinic blood pressure in predicting treatment-induced regression of left ventricular hypertrophy. SAMPLE Study Group. Circulation 1997, 95(6):1464-1470.

11. Omboni S, Ravogli A, Parati G, Zanchetti A, Mancia G: Prognostic value of ambulatory blood pressure monitoring. J Hypertens Supp/ 1991, 9(3):S25-S28.

12. Staessen JA, Asmar R, De Buyzere M, et al: Task Force II: blood pressure measurement and cardiovascular outcome. Blood Press Monit 2001, 6(6):355-370.

13. Staessen JA, Beilin L, Parati G, Waeber B, White W: Task force IV: clinical use of ambulatory blood pressure monitoring: participants of the 1999 consensus conference on ambulatory blood pressure monitoring. Blood Press Monit 1999, 4(6):319-331.

14. Abasolo Galdos RM, Aizpuru Barandiaran F, Mar Medina J, RuizdeGaunaLopezdeHeredia R, Domingo Rico C: White coat and nondipper hypertension in patients recently diagnosed with mild hypertension. Aten Primaria 1999, 23(6):332-338.

15. Cihak R, Widimsky J: 24-hour ambulatory monitoring of blood pressure and the diagnosis of resistant hypertension. Cas Lek Cesk 1989, 128(46):1456-1460.

16. Devereux RB, Pickering TG: Relationship between ambulatory or exercise blood pressure and left ventricular structure: prognostic implications. J Hypertens Supp/ 1990, 8(6):S125-S134.

17. Bastos JM, Bertoquini S, Silva JA, Polonia J: Relationship between ambulatory blood pressure monitoring values and future occurrence of ischemic cerebrovascular and coronary events in hypertensive patients. Rev Port Cardiol 2006, 25(3):305-316.

18. Kario K, Pickering TG, Umeda $Y$, et al: Morning surge in blood pressure as a predictor of silent and clinical cerebrovascular disease in elderly hypertensives: a prospective study. Circulation 2003, 107(10):1401-1406.
19. Nakano S, Konishi K, Furuya K, et al: A prognostic role of mean 24-h pulse pressure level for cardiovascular events in type 2 diabetic subjects under 60 years of age. Diabetes Care 2005, 28(1):95-100.

20. Polonia J, Amado P, Barbosa $L$, et al: Morning rise, morning surge and daytime variability of blood pressure and cardiovascular target organ damage: a cross-sectional study in 743 subjects. Rev Port Cardiol 2005, 24(1):65-78

21. Long J, Gillilan R, Lee SG, Kim CR, Plantholt S: White-coat hypertension: detection and evaluation. Md Med J 1990, 39(6):555-559.

22. Mancia G, Parati G: Experience with 24-hour ambulatory blood pressure monitoring in hypertension. Am Heart J 1988, 116(4):1134-1140.

23. Pierdomenico SD, Cipollone F, Lapenna D, Bucci A, Cuccurullo F, Mezzetti A: Endothelial function in sustained and white coat hypertension. Am J Hypertens 2002, 15(11):946-952

24. Pierdomenico SD, Lapenna D, Guglielmi MD, et al: Target organ status and serum lipids in patients with white coat hypertension. Hypertension 1995, 26(5):801-807.

25. Polonia JJ, Gama GM, Silva JA, Amaral C, Martins LR, Bertoquini SE: Sequential follow-up clinic and ambulatory blood pressure evaluation in a low risk population of white-coat hypertensive patients and in normotensives. Blood Press Monit 2005, 10(2):57-64.

26. MINISTERIO-SAUDE, PORTUGAL: Portaria n567/2006 de 12 de Julho. Diario Republica 2006, I Serie B:4173-4267.

27. Polonia J, Ramalhinho V, Martins L, Saavedra J: Portuguese Society of Hypertension recommendations, assessment and treatment of hypertension. Rev Port Cardiol 2006, 25(6):649-660.

28. Angeli F, Verdecchia P, Gattobigio R, Sardone M, Reboldi G: White-coat hypertension in adults. Blood Press Monit 2005, 10(6):301-305.

29. Fagard R, Staessen J, Thijs L: Relationships between changes in left ventricular mass and in clinic and ambulatory blood pressure in response to antihypertensive therapy. J Hypertens 1997, 15(12):1493-1502.

30. Asai T, Ohkubo T, Katsuya T, et al: Endothelin-1 gene variant associates with blood pressure in obese Japanese subjects: the Ohasama Study. Hypertension 2001, 38(6):1321-1324

31. Mancia G: Clinical use of ambulatory blood pressure monitoring. Am J Hypertens 1989, 2(2 Pt 2):50S-54S.

32. Herpin D, Pickering T, Stergiou G, de Leeuw P, Germano G: Consensus conference on self-blood pressure measurement: clinical applications and diagnosis. Blood Press Monit 2000, 5(2):131-135.

33. Kotsis V, Stabouli S, Toumanidis S, et al: Target organ damage in "white coat hypertension" and "masked hypertension". Am J Hypertens 2008, 21(4):393-399

34. Gosse $P$, Bougaleb M, Egloff $P$, Lemetayer $P$, Clementy J: Clinical significance of white-coat hypertension. J Hypertens Supp/ 1994, 12(8):S43-S47.

35. Imai $Y$, Tsuji I, Nagai $K$, et al: Ambulatory blood pressure monitoring in evaluating the prevalence of hypertension in adults in Ohasama, a rural Japanese community. Hypertens Res 1996, 19(3):207-212.

36. Hond ED, Celis H, Fagard R, et al: Self-measured versus ambulatory blood pressure in the diagnosis of hypertension. J Hypertens 2003, 21(4):717-722

37. Den Hond E, Celis H, Vandenhoven G, O'Brien E, Staessen JA: Determinants of white-coat syndrome assessed by ambulatory blood pressure or selfmeasured home blood pressure. Blood Press Monit 2003, 8(1):37-40.

38. Pickering TG, Miller NH, Ogedegbe G, Krakoff LR, Artinian NT, Goff D: Call to action on use and reimbursement for home blood pressure monitoring: Executive Summary. A joint scientific statement from the American Heart Association, American Society of Hypertension, and Preventive Cardiovascular Nurses Association. J Clin Hypertens (Greenwich) 2008, 10(6):467-476

39. Gosse P, Promax H, Durandet P, Clementy J: 'White coat' hypertension: no harm for the heart. Hypertension 1993, 22(5):766-770.

40. Sheps SG: Cost considerations of ambulatory blood pressure monitoring. J Hypertens Supp/ 1990, 8(6):S29-S31.

41. Lorgelly $P$, Siatis I, Manning G: Is ambulatory blood pressure monitoring cost effective in the routine surveillance of treated hypertensive patients in primary care? Br Med J Gen Pract 2003, 53(3):794-796.

doi:10.1186/1471-2261-13-57

Cite this article as: Pessanha et al:: Diagnostic value and cost-benefit analysis of 24 hours ambulatory blood pressure monitoring in primary care in Portugal. BMC Cardiovascular Disorders 2013 13:57. 